\title{
Engendering Budgets: Assessing Personal Consciousness of Policy Actors towards Gender Responsive Budgeting (GRB)
}

\author{
Anis Farahwahida Mohd Karim ${ }^{1,2 *}$ and Noraida Endut ${ }^{1}$ \\ ${ }^{I}$ Centre for Research on Women and Gender (KANITA), Universiti Sains Malaysia (USM), \\ Malaysia \\ ${ }^{2}$ School of Social and Economic Development, Universiti Malaysia Terengganu (UMT), \\ Malaysia
}

\begin{abstract}
This paper attempts to examine personal consciousness among policy actors towards Gender Responsive Budgeting (GRB) initiative in connection with gender equality in Malaysia. The paper concerns in assessing on personal consciousness as a part of challenges to implement GRB in the Ministry of Women, Family and Community Development (MWFCD) and Ministry of Finance (MOF). Available western studies have shown that GRB or gender budget processes still encounter various issues such as lack of concept understanding itself and support from the organisational top management. Malaysia's GRB initiative was introduced in the mid-2003. Nevertheless, even after 12 years since successful of Manual on Gender Budgeting publication, a very low personal consciousness on gender related matters contribute to the least number of GRB and gender-related awareness programmes organised for policy actors. The low personal gender consciousness among policy actors was identified as an ultimate challenge in implementing GRB in Malaysia. In collecting data, this study has carried out a series of face-to-face interviews with eight top policy actors; and a desk review of various documents related to gender awareness and budgeting works. The data was analysed on personal consciousness which is the first quadrant of Individual and Organisational Change Matrix introduced by Rao and Kelleher (2002). The paper concludes that GRB initiative needs support and cooperation from various stakeholders to develop personal consciousness on gender among policy actors and enable them to have deep understanding on GRB processes. So, this paper recommends that the MWFCD and MOF need to enhance women participation in budgetary debates and decision making processes. Additionally, the top management of the ministries has to support the initiative through GRB's advocacy, effective policy cascading as well as lobbying programmes related to gender understanding.
\end{abstract}

Keywords: Gender Responsive Budgeting (GRB); public policy; personal consciousness; gender equality.

\section{Introduction}

Since 1950's, many strategies towards gender equality have been intervening in recognising women's participation in country's major economic, politics and social sections. The involvement of women in all spheres of life appears to be significant across the globe since it was mentioned at the Fourth World Conference on Women in Beijing in 1995, in building commitment towards promoting gender equality. Therefore, various commitments have been made to reflect on changes in the macroeconomic level and social policy mechanisms in most countries. Basically, more than 100 countries have expressed commitments to achieve gender equality and gender mainstreaming, yet there in undeniably gap between policy statements and implementation processes (i.e. how government earns and spends money). A gap between participation and consultation in formulating new government policies and legislation, as well as in public resources allocation are often exists (Moser, 2012; Elson, 2002). To ensure on gender equality practises, most of governments preferred to engender their public 
budgets through Gender Responsive Budgeting (GRB) initiative. The main focus to be engendered is usually on the use of public resources. Still, there is no one recipe that fits each other. The initiative is country-specific and really accordance with its government's willingness and political influence (Budlender and Hewitt, 2003, Balmori, 2003). As a policy in action, GRB was initiated as a global strategy for promoting gender equality in Malaysia, especially in terms of the equal allocation of public resources for women and men. More likely, GRB is an economic tool to ensure that both women and men enjoy equal opportunities and receive same benefits from all aspects that they had involved. Besides, GRB is a step taken in ensuring the women's voices are heard and allow for a transition from their inspiration to action.

This paper attempts to examine personal consciousness of policy actors towards GRB initiative in connection with gender equality in Malaysia. The paper is concerned with assessing personal consciousness as a part of challenges to implementing GRB in Malaysia's Ministry of Women, Family and Community Development (MWFCD) and Ministry of Finance (MOF). This paper specifically examines the policy actors' personal consciousness of GRB and gender related matters. In this study, the policy actors refer to policy makers and policy implementers of the ministries. The main outcome of this study is expected to enrich various policy actors with useful information on how to engender government budgets so as to bring about a culture of gender equality in an organisational environment. Therefore, in moving towards gender equality organisation, policy actors must have a high personal consciousness of GRB and gender-related issues.

In the next section, the paper will discuss the concepts, origin and rationale of GRB as a whole. The paper then highlights how personal gender consciousness among policy actors has been identified as the ultimate challenge in implementing GRB in both MWFCD and MOF. It follows with conclusion and recommendations based on the challenges presented.

\section{The Concept, Origins and Rationale for Gender Responsive Budgeting (GRB)}

Gender Responsive Budgeting (GRB) or gender budgets have been introduced in varying forms across the globe. Several terms have been used in various studies to describe public budgets that integrate gender perspectives into government budgetary processes. In the 1990s, the term that Australian and South African widely used to refer to the initiative was "women's budget". The term "Gender Responsive Budgeting" and "Gender Budgets" has been used interchangeably with several terms, namely "Gender Responsive Budget", "Women's Budget" and "Budget Statements for Women" in most researches since 1970s. Rubin and Bartle (2005) indicated that all these terms, including "Gender-Sensitive Budget" are often used by the scholars and policy makers, but substantively referred to the same concept in the most gender and feminist researches.

Even if so many terms are used to explain the term, it should be made clear that the women's budget or gendersensitive budget is neither a separate budget for women or men nor a budget that is equally divided (Budlender et al., 1998, Budlender, 2007, Chakraborthy, 2010, 2014). From the feminist perspective, the Gender Responsive Budget (GRB) is a budget where the expenditure and revenue are being disaggregated according to its different impacts on women and men needs, i.e. incomes, health, education as well as nutrition, whereby it will automatically affects living standard of women or men from different groups, either to be upgraded or deteriorated (Budlender, et al., 2002). GRB is also known as an analysis of government's budget that to establish the differential impacts on women and men, regardless of different groups and somehow to illustrate the government's gender commitment by translating it into budgetary commitments. Kovsted (2008) pointed out that gender budget is a segmentation of government budget to determine gender-differential impacts and then translate it into gender budget commitments based on the gap between policy statements and public resource allocation. Durojaya et al. (2010) argued that the GRB is not considered as a new intervention or an established methodology, but rather a tool of strategies for gendered budget including budget policies and analysis to achieve gender equality. Various scholars have given many GRB perspectives based on their studies and understanding. However, the authors decided that the term GRB should be defined as a process of doing 
gendered budget, not referring to a specific budget proposal or document. GRB as a process will be used as a tool and strategy to examine the personal consciousness of policy actors on gender-related issues.

The first gender budget initiatives were started in Australia in 1984 as a mechanism to assess the impact of the national budget on women and girls in the country. Later, in the mid-1990s, this initiative was followed by South Africa and Philippines, thus demonstrated continuous adoption of that particular budget in most governments and women's organisation across the world right after the Beijing Conference in 1995. More than 100 countries around the world are currently using this mechanism to ensure equal distribution of resources between women and men in their countries in an effort to promote gender equality. It has since become part of advocacy for gender equality and its related issues are elevated to the attention of legislators and other budget decision makers, for example, the allocation of public resources and other.

Available western studies have shown that GRB or gender budget process still encounter various issues such as lack of concept understanding and support from the organisational top management. Even in Malaysia, after 12 years of successful publication of the Manual on Gender Budgeting, a very low personal consciousness among policy makers on gender-related issues directly minimise the number of GRB and gender-related awareness programmes organised at the ministry level for policy actors. The internalisation of gender into the government's budget has its rationale. Basically, according to Kovsted (2008), the implementation of GRB will (i) improve efficiency of government delivery services through gendered budget as this will encourage for topdown discussion between governments and international development cooperation organisations, (ii) become a bridge to mainstreaming gender and government's on-going effort to prepare for sound budgets whilst ensuring for sustained economic growth and development, and (iii) connects between gender-oriented NGOs and the government, which allow for open dialogue about and assist the government in enhancing gender equality.

\section{Gender Responsive Budgeting (GRB) in Malaysia}

In Malaysia, the Gender Responsive Budgeting (GRB) started in the year 2000 when the Tun Dr. Mahathir Mohammad expressed on the needs of gender budgeting in Regional Steering Committee of women in AsiaPacific (Malaysian Ministry of Women, Family and Community Development, 2005). Then, efforts to mainstream gender to achieve gender equality were begun since Malaysia's National Policy on Women (1989). The idea of supporting the need for gender budget work was documented in the policy through several sections that demonstrated that since the 1980s, the Malaysian Government has realised the importance of integrating gender into development planning and its national budget. However, only in year 2001, the commitment towards GRB become more realistic when the establishment of the Ministry of Women, Family and Community Development (MWFCD) which responsible for promoting gender equity and women's development in Malaysia. The ministry then plays its vital role in promoting women and development as stated in the Eight Malaysia Plan, gender equality commitments as set out in the Federal Constitution and gender equality resolutions as stated in the Convention on the Elimination of All Forms of Discrimination against Women (CEDAW). In the mid-2003, the effort began with participation of four pilot ministries in initiating the GRB on their selected development programmes, namely Education, Human Resource, Health and Rural and Regional Development. However, the status of implementation status appears to be silent at ministry level when the authors observed there is less documentation on the progress of GRB in Malaysia.

Nevertheless, at the State level, due to high personal consciousness of the GRB and gender needs, the Penang State Government took a step to spark for implementation of GRB through collaboration with Penang Women Development Centre (PWDC). In 2012, PWDC was then spearheaded the GRB initiative in Penang State by applying a combination of models of GRB and Participatory Budgeting (PB). The models formally known as Gender Responsive and Participatory Budgeting (GRPB) developed to influence on public expenditure at two flats at PPR Jalan Sungai and PPR Ampangan flats, with a strong collaboration with the Penang Island Municipal Council (MPPP); and the Seberang Perai Municipal Councils (MPSP). Kamarudin (2016) 
emphasised that during this GRPB initiatives implementation, the main concerns of the state government and councils were building maintenance and cleanliness due to high public complains. It was reported some positive development of the pilot projects. Equal facilities have been provided to flat communities regardless of youth, older and person-with-disable can fully utilise the amenities provided.

\section{What is Personal Consciousness?}

Making a significant impact on gender equality in organisation, it should undergo some changes. Changes should cover all related aspects of the institution and organisation. According to Kabeer (1994), an institution refers to rules in achieving social or economic ends, while an organisation demonstrated more on social structures created to accomplish one ends and embody institutions prevalent in society. So, the key element of an institution is its people, and the key component for changes in organisational culture is individual personal consciousness of gender.

The critical concern of this paper is personal consciousness, which be based on The Gender at Work Analytical Approach developed by Rao and Kelleher (2002). In the framework, personal consciousness is placed at the first quadrant, illustrating how important this cluster is in influencing believe and culture in a particular organisation as well as institution. Personal consciousness is the informal institution that directly gives influence on cultural norms and practices, thus later affects individual access to resources and institutional rules, laws and policies at the formal institution. The word consciousness is allied closely to awareness and interchangeably used in most researches. Psychologically, Scott's (1918) research found that the two terms were not exactly similar to each other, where awareness was illustrated as a broader term and always had more outward meaning than consciousness. However, term consciousness and awareness will be used and considered to have the same meaning interchangeably in this study. Besides, it must be clear that all consciousness is personal consciousness.

\section{Research Methodology}

This paper's findings are derived from the results of qualitative interpretative research on internalisation of GRB and its implementation through a gender lens among policy actors. A series of face-to-face interviews were conducted with eight top policy actors, followed by a desk review of various documents related to gender awareness and budgeting works at the Putrajaya, Kuala Lumpur. The selected ministries for this study were MWFCD and MOF. The eight respondents were the policy actors consisting of two policy makers and six policy implementers from both ministries. Structured and semi-structured interviews in formal setting were conducted to allow perspective of policy actors to be heard while at the same time their awareness of the GRB can be evaluated.

Before the interview sessions began, the respondents were asked to provide tacit consent by reading and signing two types of consent forms (interview and publication) in addition to recording verbal consent to ensure on trustworthiness and voluntary participation. A copy of the interview and publication consent forms that contain the details of the research and researchers was given to the respondents. The transcribed interview narratives by policy actors were selected and analyses. The authors using the five steps qualitative analysis process suggested by Patton (1990) and themes emerging from the data were carefully verified. The policy actors shared information about their background, perspective on gender and GRB and personal work-life stories. The table 1 below summaries detail of the eight policy actors who participated in the study. Aged between 34 and 47 years old from the group of management and professionals, they were differentiated according to the grade they possessed currently. Seven of them were married with children (with the exception of two still having no child), and only two single. Five of them obtained Master's Degree and the other three have a Bachelor's Degree. To provide confidentiality, all of them are identified using pseudonym agreed with them, see Table 1. 
Table 1 Detail of Respondents

\begin{tabular}{|l|l|l|l|l|l|l|}
\hline Pseudonym & Gender & $\begin{array}{l}\text { Marital } \\
\text { Status }\end{array}$ & Age & $\begin{array}{l}\text { Educational } \\
\text { Level }\end{array}$ & $\begin{array}{l}\text { Year of Service in } \\
\text { current } \\
\text { division/unit }\end{array}$ & $\begin{array}{l}\text { Type of Policy } \\
\text { Actors }\end{array}$ \\
\hline Ruby & Female & Married & 33 & Bachelor Degree & $5-10$ years & $\begin{array}{l}\text { Policy } \\
\text { Implementer (PI) }\end{array}$ \\
\hline Farah & Female & Single & 35 & Master's Degree & Less than 5 years & $\begin{array}{l}\text { Policy } \\
\text { Implementer (PI) }\end{array}$ \\
\hline Joshua & Male & Married & 47 & Master's Degree & $5-10$ years & $\begin{array}{l}\text { Policy Maker } \\
\text { (PM) }\end{array}$ \\
\hline Faizul & Male & Married & 38 & Master's Degree & Less than 5 years & $\begin{array}{l}\text { Policy } \\
\text { Implementer (PI) }\end{array}$ \\
\hline Radzi & Male & Married & 38 & Bachelor Degree & Less than 5 years & $\begin{array}{l}\text { Policy } \\
\text { Implementer (PI) }\end{array}$ \\
\hline Zihan & Female & Married & 45 & Master's Degree & Less than 5 years & $\begin{array}{l}\text { Policy Maker } \\
\text { (PM) }\end{array}$ \\
\hline Faridah & Female & Single & 39 & Bachelor Degree & 5-10 years & $\begin{array}{l}\text { Policy } \\
\text { Implementer (PI) }\end{array}$ \\
\hline Rosy & Female & Married & 39 & Master's Degree & $5-10$ years & $\begin{array}{l}\text { Policy Maker } \\
\text { (PM) }\end{array}$ \\
\hline
\end{tabular}

\section{Findings}

Rao and Kelleher (2002) in their framework of Individual and Organisational Change Matrix placed personal consciousness as the first quadrant (Rao and Kelleher, 2002; 2005), which illustrated how informal institutions in an individual could influence on changes in organisation. The framework basically links organisational change, institutional change and gender equality. The top left and right quadrants consisted of personal consciousness and access to resources, to think about how change can happen from an individual perspective. At the systemic level, the bottom left and right consisted of deep structure and visible powers exercised through rules and policies. Therefore, personal gender consciousness is considered to be the key element that can affects the remaining three quadrants, i.e. access to resources, formal rules and policies, as well as internal culture and deep structure. The low personal gender consciousness among policy actors was identified as an ultimate challenge in implementing GRB in Malaysia. So, this paper selects MWFCD and MOF as both ministries are the key gears of GRB implementation in Malaysia. MWFCD as a responsible ministry to promote and raise public perception of the role of women in institutions for the sake of Malaysia's development agenda is the forefront for GRB initiative, while MOF is the core financial supports ministry for the initiative. The collaboration between the two leading ministries somehow very significance and expected to spark changes in organisational work culture to be more gender sensitive, especially in terms of its own budgetary processes, not to mention on the other four piloted ministries. Findings on personal consciousness among policy actors will be discussed on the basis of three main themes, as set out below.

\section{Policy Actors' Understanding of Gender Concept and Related Issues}

The findings of this study exposed that understanding of gender and its related issues among the top management officers influenced the level of internalisation of gender into the current budgetary process at MWFCD and MOF. Generally, all informants know about gender as this concept has been introduced and internalised in the current situation in Malaysia. Undeniably, they were familiarised with the term gender and it is appropriate to discuss the concept with them. However, their understanding of gender is still limited, even as they are MWFCD and MOF officers. The findings showed that most of them know the concept of gender and are able to differentiate the gender needs. Nevertheless, it is illustrated that not all informants who knows about the gender term have fully understood about the concept. Some of them felt the gender concept is more to talk about women. Holding a post as a decision-maker for his division at MWFCD, Joshua, an informant with 
knowledge and understanding of the gender concept, admitted this fact. Thus, his statement shows that most decision makers in the ministry still do not have a clear understanding of the gender concept.

“...Actually, in the Malaysian Government, there are a limited number of people who knows and understands about GRB. Most people who supposed to know can no longer remember the concept. They are just forgetting. And because of officers hopping here and there, only a few officers left who still understands and know about GRB as well as gender concepts."

(Joshua, MWFCD, PM)

Whereas, Farah and Faizul understood gender concept as below:

"...Gender is about men and women. Other than that, do not consider it as a gender. I supposed they do not exist. Gender is about both men and women. So, I think sex and gender are the same because there is no third sex. It is just women and men. Other types like transgender are not considered as gender. I still have less understanding of what gender is and its related matters. Because I am more focused on development and site so I cannot see the relationship between my job task and gender. Because I assumed that gender is more on Policy Division. Maybe because I am attached to the Department of Development so I mean the substance does not really reach me."

(Farah, MWFCD, PI)

"...Gender and sex are the same. It is easy to understand that gender is about sex, either men or women."

(Faizul, MWFCD, PI)

Being attached to MOF for nearly ten years, Zihan as Head of Training Section, she is testified on how she understands gender and its related concepts. At the same time she also revealed that her officers know nothing about GRB and have low understanding about gender matters.

“...Gender is not about women, it is including men. Also included are person with disabilities (PWDs) and all vulnerable groups in societies, which means the groups that are easily marginalised and discriminated against. Sex and gender are different. Sex refers to women or men like that, gender is broad. When we talked about vulnerable groups, so that is also considered as gender matters [...]Gender means every group, including PWDs, elderly, children, single mother, every minority group like indigenous people, because in the mentioned groups, there are existence of men and women, boys and girls [...] All this while, MWFCD never organised any GRB training courses or gender-related training courses. Even if you go and see my officers outside, they absolutely do not know what GRB is."

(Zihan, MOF, PM)

Besides, during her service, she just coordinated Outcome-Based Budgeting training courses at The National Institute of Public Administration (well-known as Institut Tadbir Awam Negara (INTAN)) and ministries to all budgetary officers, and not to provide any gender budget courses since it is clearly the responsibility of MWFCD. She also explained that when MOF asks for all MWFCD budgetary officers for data refinement training courses, one specific top ministry officer refuse the courses.

“...We tried to organise OBB training course in MWFCD in 2016 because we identified that their data presentation was rather worse, but one specific top officer refused to approve the data refinement courses to be organised. Consequently, we need to ask for Chief Secretary and related top officers to intervene in this matter and finally we able to run the course".

(Zihan, MOF, PM) 
Faridah, married with two children, had served at MOF's Budgetary Division for 15 years explaining her understanding of gender and its related matters as follows:

“...Gender refers to sex, that is women and men, girls and boys. I just understand to that extend. Sex is also like women and men [...] Gender equality means that men and women will have similar rights. But for me, men are leaders in Islam will enjoy more portions in terms of properties, rights and so on. So, I have less understanding about gender issues. I do not know why women are still seeking for more rights because we (women and men) are treated equally in Malaysia. I do not think there is any oppression." (Faridah, MOF, PM)

From the findings, it shows that all interviewed respondents know the gender term, but not all of them accurately understand the gender concept and its related issues. It is realised that only the two policy makers, Joshua and Zihan have good understanding of gender concepts. In general, gender concept is developed due to masculinities and femininity features grows from the current social, political and economic factors (Einhorn and Sever, 2005). However, the dominant factors are more towards masculinities or men in most circumstances. As a result, women seem to have unconsciously accepted this atmosphere. So, in this particular atmosphere, women indirectly had allowed their environment to be marginalised by male counterparts. This undoubtedly explained their personal gender consciousness, which illustrated directly from their understanding of gender concepts and its related matters. Their interpretation about gender and its related matters obviously shows policy implementer's low personal consciousness of gender.

\section{Policy Actor's Understanding of Budgetary Processes and GRB}

Most of the policy actors have knowledge of the budgetary process since they are directly involved in preparing the budgetary proposal for their ministries. Nevertheless, most of them do not recognise that gender elements are already incorporated in the Outcome Based Budgeting (OBB), which is a current national budgetary system. This situation illustrated that most of the informants do not really understand the GRB process as well as OBB itself. A MWFCD senior male officer responded this question by:

“...Before this, I explained to MOE officers when they said they were gender neutral. They said they treated men and women equally all this while so why gender budget matters. There is no problem before. Again, they said they cannot brain what is gender budgeting. He (MOE policy male officer) said "we did not do anything". I said, "No, you did, it just you do not know you are doing it." For instance, in past, you have got to pay for education in the past; now it's free. So, that is the gender budgeting effort. You think you have not done anything about gender matters, but at that junction you have actually change your policy direction to go for gender budgeting. But you do not realise that you did gender budgeting all this while. So, actually they do not understand even the basis of gender concept."

(Joshua, MWFCD, PM)

Additionally, Joshua's statement has been proved by the statements given by his junior officer. Radzi, currently a person who responsible for Welfare Department's budgetary processes. He is a Gender Focal Point (GFP) at his previous ministry, supposed to have better knowledge of gender and existing budgetary process, but surprisingly he has very little understanding of the meaning of 'outcome' in the OBB system. When the authors asked him, he then linked the term outcome of the system as ministry income. He also admitted his low understanding of GRB and do not know how to implement it.

“...Talking about the outcome, any government departments prohibited to generate own income unless local authorities. We provide service at the Welfare Department itself and not money-oriented. So, we have no outcome because we are delivering services to our target clients and not earning our own income. But, if the 
Royal Customs Department, they will generate income. Frankly speaking, I know little about GRB but I still blurred about how it should be implemented."

(Radzi, MWFCD, PI)

In addition, to gain a deeper understanding about the ministries' budgetary processes, the authors questioned the data collection processes in the respective ministries. In preparing gender budget analysis, the budgetary officer must have complete gender disaggregated data between women and men, including their total numbers. Ruby and Faizul responded to the MWFCD data collection processes by:

“...It depends on the ministry's direction and its agencies. For example like Welfare Department as it focusing on its target clients such as elderly, children, Person with Disabilities (PWDs) and so on. So, if the agency wishes to apply the allocation to its specific target clients, the available data will be disaggregated by sex, race, needs, and types of disability and so on. If there is no need for disaggregated data, all data will be combined."

(Ruby, MWFCD, PI)

“...Generally, data had been classified according to sex. For example, Welfare Department, they can give detailed data on Person with Disabilities (PWDs), the types of disabilities, total number of male and female, because they have a system called 'Sistem Maklumat Pendaftaran OKU'. All registered PWDs have their complete data. The data can be details depending on the state or region, and age group. So, like us, we directly dependent on agencies for any kind of data related to our portfolio. If any outside organisation asking for data and want to know about the number of registered PWDs, they will come to us and we will find the data. This is the Data Unit function, we gather data."

(Faizul, MWFCD, PI)

Talking about the budgetary process in both ministries, Zihan, who is responsible for OBB training for all ministries, is still in doubt as to how well budgetary officers understood the gender elements that exist in the current OBB. She added the lack of understanding of the process of preparing national budgets among policy actors is the main challenge of implementing OBB, not to mention of the GRB implementation.

“...Currently, when we (MOF) talk about OBB, the issue is they (all ministries' officers) will focus on the word 'budgeting' at the end of the term. They cannot see that OBB process needs concentration starting from the ministry's budgetary planning. The ministries' officers were confused; they think OBB is only about money, whereas it started from the planning stage. Actually, getting OBB buy-in among officers is not easy. When we talked about OBB, it only has to be financial matters. So, that is perceptions of officers. They only think that OBB is about money, although OBB is about planning to achieve specific outcomes."

(Zihan, MOF, PM)

Rosy, as a Budget Review Officer (BRO) at MOF, has supported Zihan's statement above. Rosy has served the National Budgetary Office for five years disclosing that in the process of collecting data to be filled in OBB system, most of the ministries never prepared for gender disaggregated data even if they have that raw data. They were unaware that they already had the data. This directly indicates that the personal consciousness of budgetary officers on their target clients' needs is still lower. Therefore, the process of data collection is done without really examining the different gender needs of the target clients.

“...Most of the time, MOF will get the lump-sum data. The data is not separated to target client group of each programme, whereas these ministries already have the data. It is just that the way a report is written is not 
always aligned with what we are asking for. This is a problem for us if we want to make evaluation. BROs need to contact them back and ask for the expected data."

(Rosy, MOF, PI)

Findings show that most of the respondents have a surface understanding of the budgetary process. Yet, they still have low understanding of OBB's basic concept and whole process itself; even since 2003 this system has been fully adopted. Obviously, this situation portrays the incapability of budgetary officers in the MWFCD and MOF to understand the current national budgetary system i.e OBB. The gender elements provided in the system are not considered as important aspects to be focused on. Therefore gender analysis is not carried out as a basis for preparing a gendered national budget. Therefore, this situation keeps the researcher wondering about the GRB process in this ministry which so called a policy in action. In any circumstances, this setting will affects national development due to failure of budgetary officers to have a deep understanding of the core process of the national budgetary system. Consequently, this influenced the understanding of officers not only on OBB itself, but also on GRB at the same time.

\section{Policy Actors' Personal Consciousness on Gender and GRB}

Gender awareness is referred to the knowledge about gender and awareness towards it related matters (Verdonk et.al, 2008). Gender awareness or consciousness is a part of gender practices. Thus, it directly could influence individual actions and day-to day decision making. Basically, the behind idea of gender awareness or consciousness is to give appreciation to both women and men in all aspects of life, whether at home, at workplace or anywhere, so that they can compete equally to show their self-potential. Gender related matters are on-going issues which daily discussed in any organisations. The distinctive part is either the officers in that particular organisation realised on gender issues that they were considering.

In this study, the researchers found that all respondents had an average understanding of gender concepts and they were really familiar with the term. Yet they still have low awareness of gender matters. No profound exposure regarding gender matters contributes to low understanding and awareness among the decision-makers at the top management thus echoes the level of gender knowledge among the policy implementers in the particular ministries. Also, the appointment of Gender Focal Point (GFP) in the ministry as an agent of change in internalising gender concepts in ministerial works seemed less functional when this concept was never broadly exposed to them either. Apparently, the main function of GFP is to promote on gender concept. Nevertheless, the concept cannot be well dispersed as these GFPs also have no deeper understanding due to zero exposure about gender and its related issues.

Joshua, as the division head, he revealed that "Overall, our gender awareness is still low at MWFCD", and continues to say "even I myself at doubt, we at MWFCD, how many of us really understand the rights of women? Do they (MWFCD officers) know what they are doing?" Also, findings show that, the two respondents of the study, Farah and Radzi know the gender concept, yet they do not acquire deep personal consciousness about gender related matters and unable to identify gender issues. Farah later contradicted her opinion when she commented there was no gender stereotype issue in MWFCD but at the same time admitted that women have less opportunity to get promoted to a higher position. Farah reacted that:

"...I suppose there is no gender stereotype in here which is, the male bosses may not think of like stereotyping any women because women are majority here. In this Ministry of Women, men are the minority. [...] I see women having less opportunity to get resources like job promotion at the Deputy Secretary General (DSG) level. Most of them were men. But, at Grade 41, there are mostly women. Mostly men are the ones holding a higher position such as the Public Service Premier Post and above, these are the higher level officers who mainly decide in the ministry. These positions have a great competition between women and men. It is a common where the head of government departments and agencies are all men." 
Radzi, who married a teacher with a child, shared his views on gender equality and concluded that women in Malaysia face no restrictions on public resources. He then remarked:

“...In my opinion, there are no gender inequality issues in Malaysia because Malaysians were given equal opportunities, for instance, in terms of educational opportunities and public facilities. There is no restriction for certain gender only which is everybody can experience the same facilities [...] Women and men are different physically but have the same capabilities. Women in Malaysia have never been restricted to voice up opinions and acquired room for decision-making. Compared to the others countries, women are quite restricted in certain aspects, like Arab women, they are prohibited to drive a car. In Malaysia, there is no such restriction such as studying at university."

(Radzi, MWFCD, PI)

In addition, Faridah who has been involved in reviewing the budgetary processes and documentations of MOF for more than seven years has low personal consciousness of gender roles and gender equality concepts. Therefore, with her statement below, the authors claimed that she is ignorant to gender equality commitment, therefore possibly opposed GRB in her budgets work.

“...Not in all aspects women have to be like men. Why are women eager to be like men? Why do women want to do all the things that men do? For me, it should be depend on the situation. If you are not desperate enough, why do you have to do an extreme job? There are many other jobs that women can do while maintaining their politeness and gentleness. Because for me, it is so weird when the healthy husband stays at home taking care of kids and doing house chores while the wife goes outside to earn income and hold a higher position. For me, money is the man's matter and a wife simply relieves the financial discrepancy. It is not compulsory for women to earn family living."

(Faridah, MWFCD, PM)

\section{Discussion}

In this section, the authors assess on the personal consciousness of policy actors based on Rao and Kelleher (2002) Individual and Organisational Change Matrix. This framework basically emphasised on the achievements in one quadrant can be strategies for change in another. For example, a gender policy can be leveraged to gain more resources for women's organisations (an upper-right accomplishment), which may be invested in training local women in advocacy techniques (an upper-left change) (Green, 2016). This framework is used to evaluate on how the different aspects of the change process will fit into the different four quadrants. The focus of this paper is to look at personal consciousness in the framework's first quadrant, which clearly explained how this aspect is a root cause of any individual or organisational changes. Though, personal consciousness undeniably is influenced by deep structure that developed in the societies. This is strongly supported in Friedman and Gordezky (2011) study, where personal consciousness closely related to experience of a person, that focuses on women's and men's knowledge of and commitment to change toward equality and women's right, and willingness to take action to empower women.

The findings of this paper illustrated the extent to which policy actors' personal consciousness of gender as well as GRB implementation itself. From the voices of policy actors presented in the paper, the authors confirmed that they do not have deep understanding about gender and its related issues. Besides, the policy actors' understanding about the current budgetary system also very limited as most of them unaware that gender elements are already existing in the current OBB system. The respondents also have no exposure to real data collection process and unable to interpret the term 'outcome' correctly. The key factor contributed to the 
findings mentioned above is no clear direction from the top management to practice GRB in the work processes. The absence of firm orders by policy decision-makers on organisational structure to practice GRB directly gives a major impact on the preparation of rational national budget. The authors also have examined several budgetary documentation such as Annual Budget Preparation Process Guideline (ministerial and general) and Treasury Circulars. The treasury circulars are PB 1.1 (Bajet Berasaskan Outcome or OBB), PB 1.2 (Anggaran Perbelanjaan Persekutuan) and PB 1.3 (Garis Panduan Bagi Penyediaan Cadangan Anggaran Perbelanjaan Persekutuan 2019) (Malaysia's Ministry of Finance Website, 2019). From the authors' observation of the documentation, the situation in both ministries illustrated where even the circulars have been issued in the preparation of gender budget, but if there is no firm direction from the top management for the implementation of GRB, the policy implementers will look lightly in focusing gender elements in the budget work. Subsequently, no gender-intensive courses have been conducted to strengthen policy actors' understanding of gender as well as OBB. Although the Manual on Gender Budgeting in Malaysia has long been published, the policy actors simply ignore the information and processes described in the manual.

Therefore, the low understanding of gender related issues and OBB processes pictures how far policy actors' personal consciousness towards gender, GRB and as well as gender equality in public policy implementation. Thus, the three dimensions provided in the study are interrelated and will have an impact on each other, demonstrating the situation that the GRB process in MWFCD and MOF is not being effectively implemented until these days.

\section{Conclusion}

Gender Responsive Budgeting (GRB) is an important tool for sound macroeconomic policies. Even so, GRB is not a simple budgetary process, thus needs deep personal consciousness to ensure high commitment by policy actors. In Malaysia, even Manual on Gender Budgeting had successfully been published in 2006, but the implementation of GRB in Malaysia is still silent and as if no change is taking place in ministerial budget works. There are still some challenges that make it difficult to implement the GRB processes in Malaysia. The main challenge identified in this paper is the low personal consciousness among policy actors of gender and its related issues due to the absence of national programme for gender awareness rising to educate on the issues of gender needs and differentiation, public resources allocation and utilisation, and the involvement of stakeholders in the public policy and budgeting processes. The paper concludes that GRB initiative needs support and cooperation from various stakeholders to develop personal consciousness of gender among policy actors. Subsequently, this will enable them to have a deep understanding on GRB processes.

So, this paper recommends that the MWFCD and MOF need to enhance women's participation in budget debates and decision making processes. The MWFCD's idea of linking women in strategic positions through its 30 per cent women at higher position will push this initiative further forward. Additionally, the top management of the both ministries have to support the initiative through GRB's advocacy, effective policy cascading as well as lobbying programmes related to gender understanding. In the future, research may be done to explore the perspective from specific gender to clearly picture the individual understanding and his or her level of gender personal consciousness. This can be further extended by GRB comparison research between genders so as to include other ministries and NGOs. Moreover, a study that analyse the effect of institutional changes on agencies' operation as well as the way it may affects the Ministries' capacity to tackle gender initiative also should be conducted. 


\section{References}

Balmori, H.H., Reeves, H. and Sever, C., 2003. Gender and budgets: Overview report. Institute of Development Studies.

Budlender, D., Sharp, R. and Allen, K., 1998. How to do a gender-sensitive budget analysis: Contemporary research and practice. Commonwealth Secretariat.

Budlender, D., Elson, D., Hewitt, G. and Mukhopadhyay, T. eds., 2002. Gender budgets make cents: understanding gender responsive budgets. Commonwealth Secretariat.

Budlender, D. and Hewitt, G., 2003. Engendering Budgets: A practitioners' guide to understanding and implementing gender-responsive budgets. Commonwealth Secretariat.

Budlender, D., Elson, D., Hewitt, G. and Mukhodpadhyay, T., 2007. Gender-responsive call circulars and gender budget statements. Guidance Sheet Series, (1).

Chakraborty, L., 2010. Gender-sensitive fiscal policies: experience of ex-post and ex-ante gender budgets in Asia-Pacific. Bangkok: UNDP.

Chakraborty, L., 2014. Integrating time in public policy: Empirical description of gender-specific outcomes and budgeting. Levy Economics Institute of Bard College Working Paper, (785).

Durojaye, E., Keevy, I. and Oluduro, O., 2010. Gender budgeting as a tool for advancing women's health needs in Africa. European Journal of Social Sciences, 1.

Elson, D., 2002. Gender responsive budget initiatives: Key dimensions and practical examples. Gender Budget Initiatives, 16.

Friedman, M. and Gordezky, R., 2011. A holistic approach to gender equality and social justice. OD Practitioner, 43(1), p.12.

Green, D., 2016. How change happens. Oxford: Oxford University Press.

Rubin, M. and Bartle, J.R., 2005. Integrating gender into government budgets: A new perspective. Public Administration Review, 65(3), pp.259-272.

Kamarudin, S., 2016. Gender Responsive and Participatory Budgeting in Penang: The People-Oriented Model. In Gender Responsive and Participatory Budgeting (pp. 55-79). Springer, Cham.

Malaysia's Ministry of Finance Website, 2019. Homepage ( Pekeliling Perebendaharaan: Accessed 10 January 2019 from http://ppp.treasury.gov.my/

Moser, C.O., 2012. Gender planning and development: Theory, practice and training. Routledge.

Kabeer, N., 1994. Reversed realities: Gender hierarchies in development thought. Verso.

Kovsted, J. and Jacobsen, H.J., 2008. Gender-responsive budgeting in Tanzania. Date of accessed: 17/1/2019. http://www.research.net.

Patton, M.Q., 1990. Qualitative evaluation and research methods. SAGE Publications, inc.

Rao, A. and Kelleher, D., 2002. Unravelling institutionalized gender inequality.

Rao, A. and Kelleher, D., 2005. Is there life after gender mainstreaming?. Gender \& Development, 13(2), pp.5769.

Scott, W.H., 1918. Consciousness and self-consciousness. The Philosophical Review, 27(1), pp.1-20. 